\title{
Role of Plasma-Aided Manufacturing in Semiconductor Fabrication
}

\author{
Noah Hershkowitz, Fellow, IEEE
}

(Invited Review)

\begin{abstract}
A brief review is presented of the application of plasma-aided manufacturing to semiconductor fabrication. Emphasis is placed on current state-of-the-art techniques for which plasma physics plays a significant role and on current problems that remain to be solved.
\end{abstract}

\section{INTRODUCTION}

$\mathbf{P}$ LASMA-aided manufacturing takes advantage of the unique properties of plasmas to modify surfaces. It is a rapidly growing body of techniques, which are carried out over pressures ranging below 1 mtorr to greater than 1 atmosphere (atm) (see Fig. 1). At low pressures (below 1 mtorr), the presence of charged particles is the most important characteristic employed in manufacturing. Examples are ion implantation out of plasmas (PSII) [1], [2] or sputtering [3], [4]. At higher pressures (1 mtorr-1 torr), plasma etching [5] and deposition take advantage of a combination of charged particle physics, plasma chemistry, and material science. At still higher pressures (1 torr-1 atm), the plasma serves mainly as a heat source in arcjet/plasma spray applications [6]. Corona discharges [79], silent discharges [9], and intermittent glow discharges [10] are an exception. They are employed at atmospheric pressure to modify surfaces and bulk gases and take advantage of plasma chemistry.

Plasma-aided manufacturing provides one or more steps (often out of many steps) in the manufacture of a rapidly growing number of products. In some situations, such as etching of fine structures in semiconductor devices, it is the only way to achieve the needed result. In other situations, such as etching structures in flat panel displays [11], [12], it is favored because it is much more environmentally friendly than etching with wet chemistry. In other situations, such as spray coating [13], it can sometimes be more cost effective than other competing nonplasma based processes. Each situation is different. This paper concentrates on applications to semiconductor fabrication and attempts to provide a brief review of the current state-of-the-art of processing techniques with an emphasis on current problems that remain to be solved.

Size has dominated the development of ultra large scale integration semiconductor devices for many years. Wafers have increased in diameter to $200 \mathrm{~mm}$ and are progressing to $300 \mathrm{~mm}$ and beyond [14]. At the same time, the smallest

Manuscript received June 27, 1998; revised October 8, 1998.

The author is with the Engineering Research Center for Plasma-Aided Manufacturing, University of Wisconsin, Madison, WI 53706 USA (e-mail hershkowitz@engr.wisc.edu).

Publisher Item Identifier S 0093-3813(98)09706-9.

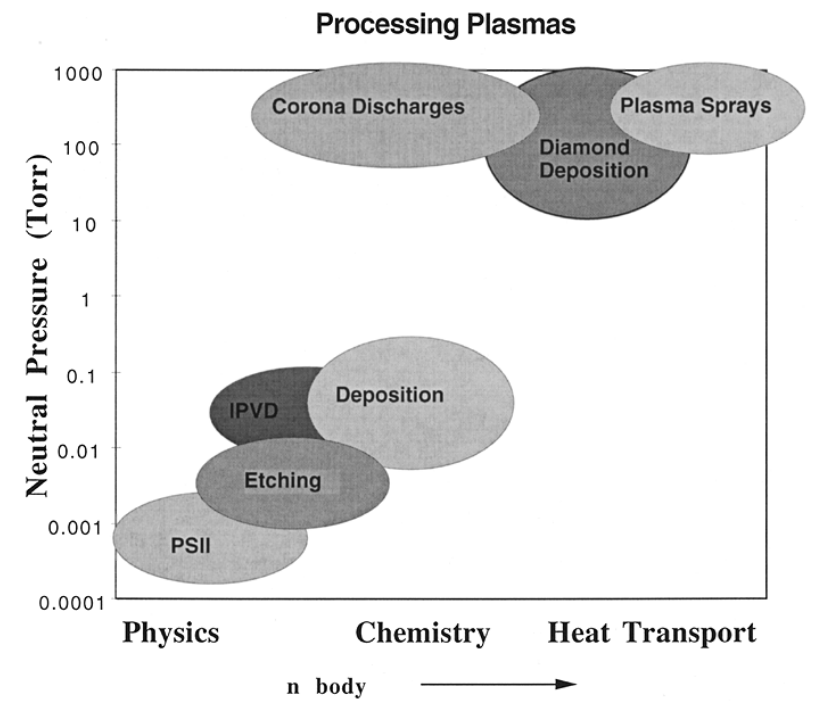

Fig. 1. Examples of important plasma-aided manufacturing techniques for surface modification with partially ionized gases. Techniques are shown schematically as a function of neutral pressure and the most relevant academic discipline.

size structures have decreased to $250 \mathrm{~nm}$ and gate thicknesses have decreased to as small as 2-3 $\mathrm{nm}$. Environmental concern has begun to develop over fluorocarbon etching which has up to now been the workhorse of etching gases. In some applications, fluorine has been replaced by chlorine.

Moore's law [15], [16], which states that there is a doubling in circuit complexity (i.e., the number of transistors per die) every 18 months, has dominated the evolution of the semiconductor industry. In 1965, Moore recognized that manufacturers had been doubling the density of at regular intervals (approximately one year) and argued they would continue to do so. The advance was a combination of approximately equal contributions from finer dimensions, bigger dies, and improved circuit and device cleverness. The halving time was re-estimated to be 18 months in 1975 with the minimum dimension halving approximately every five years. This empirical relationship has continued to the present. The semiconductor industry "National Technology Roadmap" plans the smallest size structures will decrease to $50 \mathrm{~nm}$ by 2012 (see Table I).

The transition to structures below $300 \mathrm{~nm}$ is being accompanied by a changeover from low density-high pressure plasmas (with electron densities in the order of $10^{9}$ to low $10^{10} \mathrm{~cm}^{-3}$ ) to high density-low pressure (with $n \approx 10^{10}-10^{12}$ 
TABLE I

Smallest Size Semiconductor Structure Versus YEAR FROM THE "NATIONAL TECHNOLOGY ROADMAP"

\begin{tabular}{ll} 
Year & Minimum scale size \\
1997 & $250 \mathrm{~nm}$ \\
1999 & 180 \\
2001 & 150 \\
2003 & 130 \\
2006 & 100 \\
2009 & 70 \\
2012 & 50 \\
\hline
\end{tabular}

$\mathrm{cm}^{-3}$ ) etch tools. High density plasma (HDP) can be realized with a variety of different types of plasma sources including magnetically enhanced capacitive [17], inductive [18], [19], helicon [20], [21], electron cyclotron resonant [22], and surface wave [23] tools. Although the different types of tools can in principle produce some rather different combinations of charged particles and free radical neutral species, all types are presently limited by ancillary considerations, such as photoresist survival, to plasma densities on the order of $10^{11}$ $\mathrm{cm}^{-3}$. Plasma electron temperatures $\left(T_{e}\right)$ in $\mathrm{RF}$ plasmas are the order of $3 \mathrm{eV}$ because of the requirement of ionization from the tail of the electron distribution function [24] for steady state plasmas. Ion energies at wafers are determined by the potential difference between the plasma and the wafer surface that normally occurs in a thin sheath. The operating pressure is limited to the order of 1 mtorr or higher by the need to provide vacuum pumps that can handle flow rates of tens of sccms. Note that except in the determination of electron temperature and the operating power, plasma physics is not the source of most of the constraints. Insulating polymer producing [25] gases are employed in both etching and deposition applications so dc sources or dc bias doesn't work in most cases. Instead, plasma is produced by RF or microwaves.

\section{RF ISSUES}

\section{A. Sources}

$\mathrm{RF}$ is often applied at $13.56 \mathrm{MHz}$ or $2.45 \mathrm{GHz}$ because the government allows unlimited power at these frequencies and RF hardware is relatively inexpensive. The simplest method is capacitive coupling (usually at $13.56 \mathrm{MHz}$ ). This method has the disadvantage that it can induce large potential fluctuations and associated density fluctuations in the plasma. These fluctuations can be eliminated by applying the RF symmetrically to two equal area electrodes [26]. In most capacitive processing tools, the chamber serves as one electrode with the wafer/wafer-chuck serving as the other. The smaller size of the wafer compared to the chamber increases the relative electric field at the wafer [24].

For the densities employed in plasma etching, the plasma density is proportional to the square root of the input power for capacitively coupled plasmas, while the density is linear with power for inductive sources [19], [24]. Thus inductive sources are more efficient at higher plasma densities. Conventional capacitive discharges (not enhanced by magnetic fields) are limited to densities the order of $10^{10} \mathrm{~cm}^{-3}$. The density limitation in inductive sources, on the order of $10^{12} \mathrm{~cm}^{-3}$, comes from the fact that power deposition is limited to a skin depth (proportional to $1 /(n)^{1 / 2}$ at the antenna. Helicon and surface wave sources [27], [28] can reach higher densities in magnetized systems because power deposition is not limited to the region near the antenna.

All RF HDP sources also have capacitive coupling as well because Faraday shields are not normally employed. In fact, inductive sources normally take advantage of large capacitive fields from the voltages applied to inductive coils to initiate discharges and provide sufficient plasma density to allow inductive coupling [24]. With good Faraday shielding, discharge initiation is difficult and may require temporarily raising the operating pressure [29], [30]. Transitions occur from capacitive to inductive and inductive to helicon modes during helicon source initiation [31], so it can be argued that helicon sources are most efficient and inductive sources are more efficient than capacitive sources. An alternative approach is to couple energy into electrons at the electron cyclotron resonance (ECR). The usual approach is to make use of 2.45 $\mathrm{GHz}$ with a resonant $\mathrm{B}$ field equal to 875 gauss. What is often ignored is that the resonant magnetic field corresponding to $13.56 \mathrm{MHz}$ is approximately 4.7 gauss so RF sources, which employ weak magnetic fields, may still exhibit electron cyclotron resonance [32], [33]. Processing is a local process which depends directly on the plasma parameters immediately above the wafer and only indirectly on distant parameters. Therefore, it is not surprising that $\mathrm{SiO}_{2}$ etch rates for inductive, helicon, and ECR tools were found to be identical when important charged particle and neutral species parameters were the same above the wafer [34]. The choice of which type of HDP source to use does not depend on the ability to obtain local plasma parameters. It may depend on radial uniformity, but most often depends on patent considerations or tool availability. At the present time, inductive tools make use of spiral coils [see Fig. 2(a)] or helical coils [see Fig. 2(b)] [19] or a combination.

\section{B. Wafer Self Bias}

In all HDP sources, most of the ion energy is provided by acceleration in sheath electric fields established by selfbiasing the wafer chuck. Capacitive coupling is deliberately provided to self-bias the wafer by a dedicated RF source. Substrate bias is achieved by applying RF to wafer chucks. The wafer then adjusts to a time average voltage below the plasma potential that balances electron and ion flux to the wafer. RF fluctuations in HDP plasmas are relatively small because capacitive coupling is reduced for high plasma density.

\section{Time Scales}

$\mathrm{RF}$ is the key to processing, but what are the best frequencies? What are the problems? The frequency dependence 


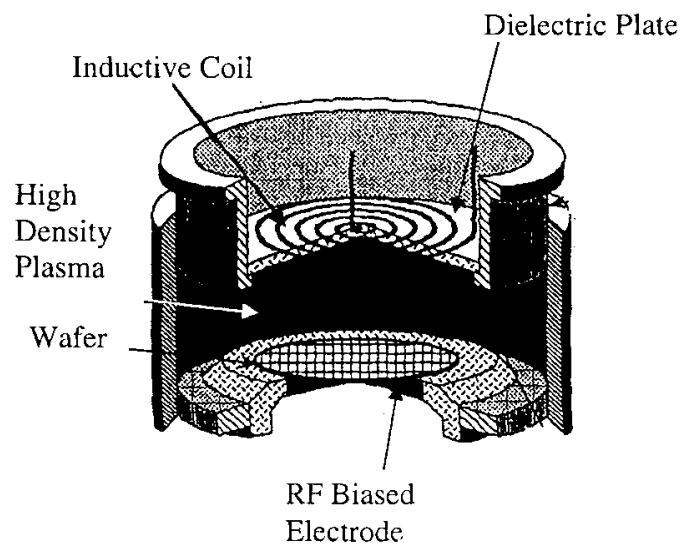

(a)

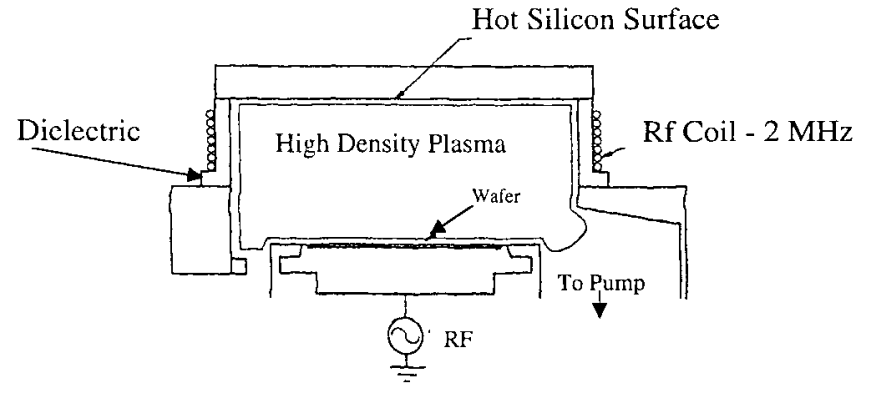

(b)

Fig. 2. Schematic diagram [19] of a planar spiral inductive source (Lam 9600) and a helical inductive source (applied omega).

depends on the ratio of the RF frequency to the various characteristic frequencies of the plasma. These include the ion and electron plasma frequencies, the ion and electron collision frequencies with neutrals and charged particles, ionization rates, etc. The ion sheath transit time is an important parameter. It can be shown to be the order of $\omega_{p i}^{-1}$, where $\omega_{p i}$ is the ion plasma frequency. For HDP tools, this time is the order of the period of the commonly used $13.56 \mathrm{MHz}$ RF. Depending on the details, ions can fall to the walls in a fraction of an RF period or over many RF cycles. The former gives a wide range of ion energies at the wafer while the latter gives a narrow spread in ion energies [35]. For electron cyclotron resonance (ECR) discharges $\omega_{r f}^{-1}$ is much less than all characteristic times except $\omega_{p e}^{-1}$ so the spread in ion energy at the wafer surface is determined by the additional RF used to self bias the wafer. Samukawa and Tsukada [36] have shown that choosing the RF frequency to be higher than the electron collision frequency results in poly-Si and $\mathrm{SiO}_{2}$ etch rates which do not depend significantly on the discharge pressure from 3-20 mtorr.

\section{Modulated/Pulsed Discharges}

Modulated/pulsed RF allows the plasma to go into afterglow and a variety of free radical species and ions, both positive and negative, can become important. Lieberman [37], [38] notes it has been claimed that such discharges can: increase $\mathrm{SiO}_{2} / \mathrm{Si}$ etch selectivity, reduce aspect ratio dependent etch effects, eliminate notching and charge build-up damage of gate oxide, increase etch uniformity, increase etch and deposition rates,

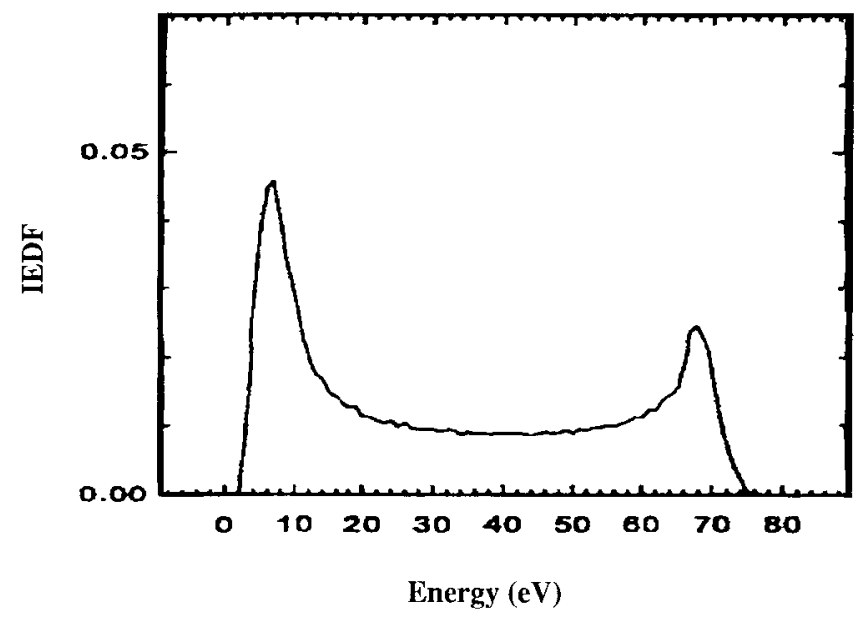

Fig. 3. Calculated IEDF of $\mathrm{Cl}^{+}$at the wafer [40]. The plasma parameters were: pressure 3.0 mtorr, RF refrequency $0.4 \mathrm{MHz}, \mathrm{RF}$ bias $60 \mathrm{~V}$ (peak-to-peak), sheath voltage $37 \mathrm{~V} T_{e}=4.0 \mathrm{eV}, n=1 \times 10^{12} \mathrm{~cm}^{-3}$.

reduce heat flux to the substrate, extend discharge pressure and power operating regimes, and reduce particulate formation.

Comparing a continuous wave $(\mathrm{CW})$ to a modulated discharge with the same time average power, the electron density can be considerably higher for the pulsed discharge. This means the modulated discharge, operated at a reduced time average power, can have the same $\mathrm{Cl}$ neutral radical flux to the walls as a higher density CW discharge. Since tools can operate at lower neutral pressures, less collisional scattering is present in the sheaths so improved anisotropic trench etching is expected. Experiments suggest aspect ratio dependent etching is reduced in modulated discharges because of reduction in sidewall charging [39].

Continuous power corresponds to lower peak density i.e., to lower $\omega_{p i}$. If the density is low enough, the ion sheath transit time can be much longer than RF period so a relatively narrow time averaged ion energy distribution function (IEDF) can result at the wafer. On the other hand, operating at high peak power can result in a time varying (IEDF). Thus the IEDF can be significantly modified by modulating the RF frequency. Varying the chuck bias frequency has a similar effect [40] (see Fig. 3). If the bias frequency is much greater than $\omega_{p i}$, ions falling through the sheath see a time average chuck bias potential and the ions can have a narrow IEDF at the wafer. If the bias frequency is much lower than $\omega_{p i}$, ions falling through the sheath see the instantaneous chuck bias potential and the ions can have a broad IEDF at the wafer.

If the plasma density is sufficiently low or if the RF fluctuation level in the plasma is low and no self bias RF is applied, the IEDF in a pulsed discharge still exhibits a range in energy because the plasma potential $\phi_{p}$, and hence the ion energy, scales with electron temperature. Charles and Boswell [41] demonstrated this effect in a helicon tool used for $\mathrm{SiO}_{2}$ deposition. In that experiment (see Fig. 4), the IEDF of a CW plasma had a single peak at $32 \mathrm{eV}$ corresponding to $\phi_{p}$, while a pulsed plasma with the same average power had two additional peaks at 50 and $15 \mathrm{eV}$. The two peaks corresponded to the high $T_{e}$ during the discharge initiation and the low $T_{e}$ late in the afterglow between pulses. 


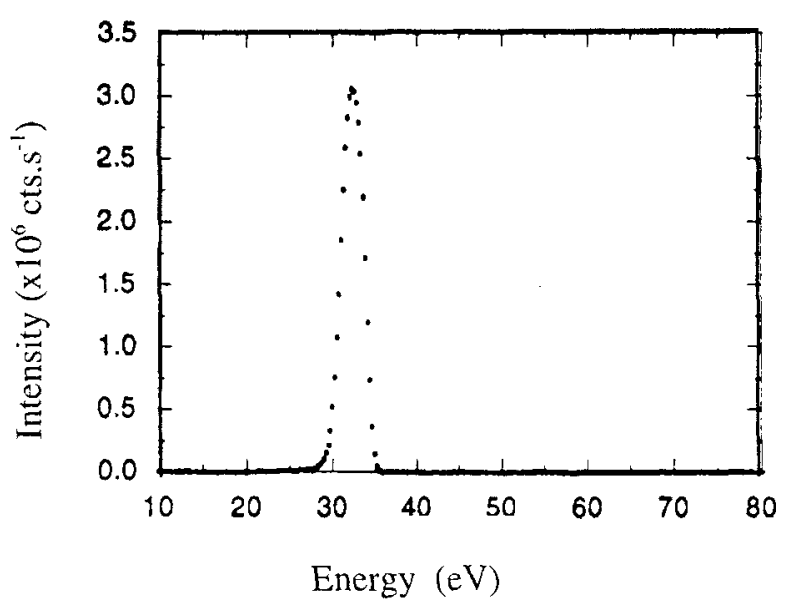

(a)

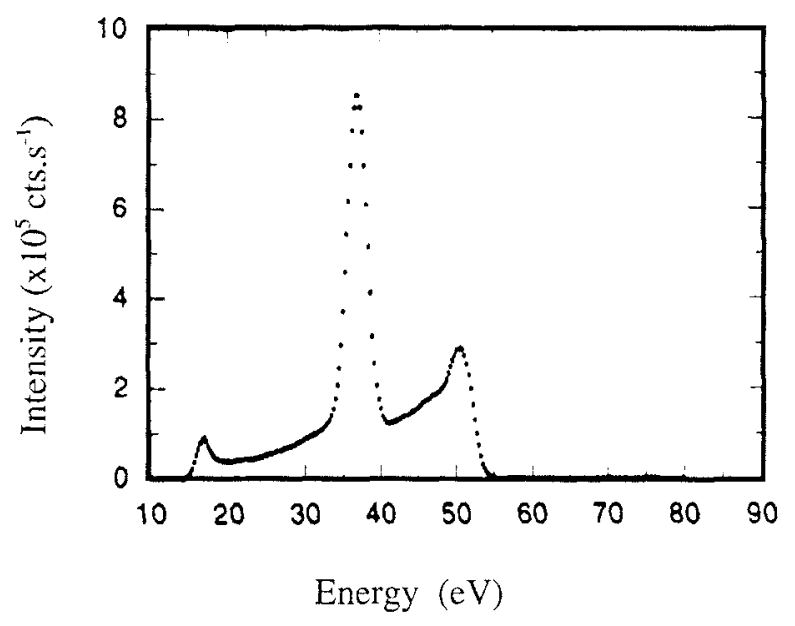

(b)

Fig. 4. IEDF of $\mathrm{O}_{2}^{+}$ions measured escaping from a helicon plasma at 800 W and 2 mtorr. (a) CW plasma. (b) Pulsed oxygen plasma 250_s-on/125_s-off [40].

\section{SPECIES ISSUES}

\section{A. Plasma Chemistry}

Plasma chemistry enormously expands the parameter space of ordinary chemistry. The presence of electrons, with much greater energies than those found in conventional chemical systems, gives rise to a variety of new free radical species. In addition, the presence of charged species means that positive, and in some cases negative, ions can deliver controlled energy to a substrate, controlled by the substrate bias energy. This allows creation of a variety of novel surfaces such as highly cross-linked Teflon or surfaces with novel surface functionalities. Under certain circumstances, ions rather than neutrals can be the precursor of polymers [42]. There is a welldeveloped understanding of the plasma chemistry involved in plasma etching of semiconductor materials by fluorocarbon and $\mathrm{Cl}_{2}$ plasmas [5], [24]. A large number of free radicals are usually present and the concentrations of many have been identified in laboratory experiments. Considerable modeling of the various reactions has also been carried out. Nevertheless, the broad discipline of plasma chemistry is now in its infancy.
Investigators have not yet taken advantage of the energy control at surfaces available for charged species or of many of the novel combinations of species present in the plasmas. With the exception of etching, most investigations are carried out in small cylindrical tools and only very limited attention is paid to the plasma. Chemists tend to ignore the ions. Plasma physicists tend to ignore many of the free radical species.

\section{B. Negative Ions}

Negative ions play an important role in many processing plasmas. They are especially important in low power/high pressure capacitive discharges [43] and in HDP afterglow plasmas [44]. Tsendin [45] was the first to suggest that negative ions are not distributed uniformly throughout the plasma but had negative ions in its core and positive ions on the edge. Lichtenberg et al. [46] solved the nonlinear diffusion equation for a positive ion, negative ion, electron plasma for a variety of assumptions. Three parameter ranges were distinguished corresponding to a range in which a parabolic approximation is appropriate, a range for which the recombination significantly modifies the ion profiles, but the electron profile is essentially flat, and a range where the electron density variation influences the solution. It was shown that a plane parallel discharge operating with chlorine gas at 30, 300, and 2000 mtorr and $n_{e 0}=10^{10} \mathrm{~cm}^{-3}$ corresponded to the three parameter regimes. A weak double layer separates the two regions. It should be noted that such structures have not yet been found experimentally.

\section{DiAGNOSTICS AND SENSORS}

\section{A. General Considerations}

Diagnostics are employed to characterize processing plasmas to provide data on charged particle plasma parameters and on neutral species parameters [47]. Charged particle parameters include plasma density, electron temperature, plasma potential, and electron and ion distribution functions. Absolute and relative densities as well as spatial profiles of neutrals and neutral temperatures can also be determined. Noninvasive, exsitu diagnostics are favored because plasma purity is often essential. Techniques include those based on optical and infrared emission and absorption [48], [49] and techniques based on lasers [50].

While a variety of diagnostics have been developed to characterize the low temperature plasmas used in plasma processing, most are not suited to be sensors. Sensors are employed to control plasmas and usually are different from diagnostics. They must be rugged and simple to use and not require any scientific interpretation, i.e., able to be operated with someone with only a high school education. The most common approach is to use whatever diagnostic/sensor data are available and hope there is a connection. End point sensors are a good example where this approach has worked. The absence of sensors that can monitor radial uniformity is now an especially serious problem. 


\section{B. Sensors}

1) End Point: End point sensors are among the best developed sensors in plasma etching. End point is the time when etching through a particular layer, e.g., $\mathrm{SiO}_{2}$, has been completed. The simplest end point sensor simply monitors optical emission at a widow. Filters are used to monitor changes in emission (at several wavelengths) which occur when the etch process goes beyond end point. End point determination becomes difficult to measure when the area being etched represents a small fraction of the total wafer area, e.g., $<1 \%$. One approach that has had some success is to monitor multiple emission lines. [51] Reitman et al. have had some success with a neural net approach [52] in which patterns from all available diagnostics are used to identify end points.

The best way to determine the end point before it is reached is to measure the etch rate real time. So far, only etch rates of transparent unpatterned wafers have been measured realtime. It is easy to make an estimate of the etch rate by counting fringes in the intensity of monochromatic light (with wavelength $\lambda$ ) reflected from the front and back surfaces of the films. New fringes are observed when the film thickness changes by $\lambda / 2$. Therefore, counting fringes is not very sensitive when the film thickness is on the order of $\lambda$, as they are for visible light where $\lambda \approx 0.5 \mu \mathrm{m}$ and film thickness on semiconductor devices the order of $1 \mu \mathrm{m}$.

2) Real Time: Sarfaty et al. [53] have solved this problem by developing a technique that measures etch rate from approximately 0.1 of a fringe. They were able to measure real time etch rates of unpatterned $\mathrm{SiO}_{2}$ and $\mathrm{Si}$ films.

A full wafer interferometer [54] can in principle be used to determine the radial etch rate uniformity. It employs interference of plasma-induced emission from the surfaces of transparent thin films on the wafer surfaces. The temporal variation of interference fringes is Fourier analyzed to determine the etch rate over the entire wafer. This sensor can be used to inspect wafers after etching or deposition is completed but cannot be used to determine end point because of the requirement of Fourier analysis. In practice, the full wafer interferometer cannot be used in most commercial plasma etch and deposition tools because adequate sensor access is not provided.

\section{Modeling}

Plasma processing tools have been successfully modeled using codes that employ analytic, Monte Carlo, or particle in cell (PIC) approaches either separately or in combination [55]. Most of the recent effort has concentrated on HDP inductive sources. Analyzes of surface wave source are now becoming available. Results on modeling collisional plasmas are summarized in a previous special issue of IEEE TRANSACTIONS on Plasma Science [56]. Because of the great difference in electron and ion time scales, many codes concentrate on accurate description of the ions and assume Boltzmann electrons. Recently, the nonlocal approach, first developed by Bernstein and Tsendin, to establishing the electron energy distribution function (EEDF) in weakly collisional plasma, has been reviewed [57].

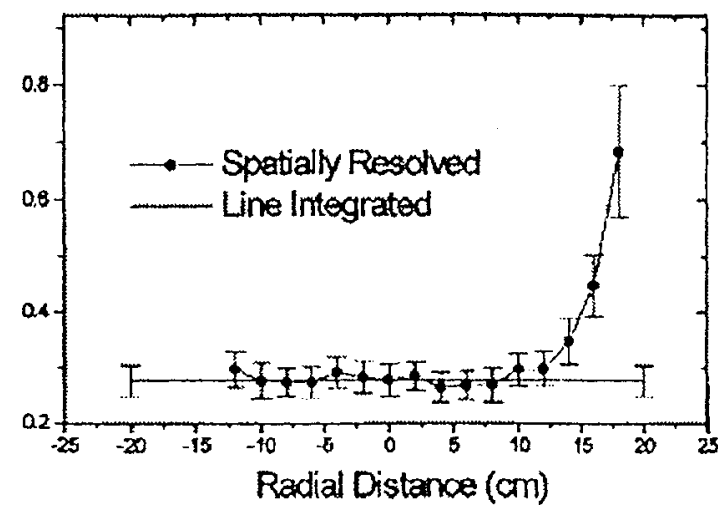

(a)

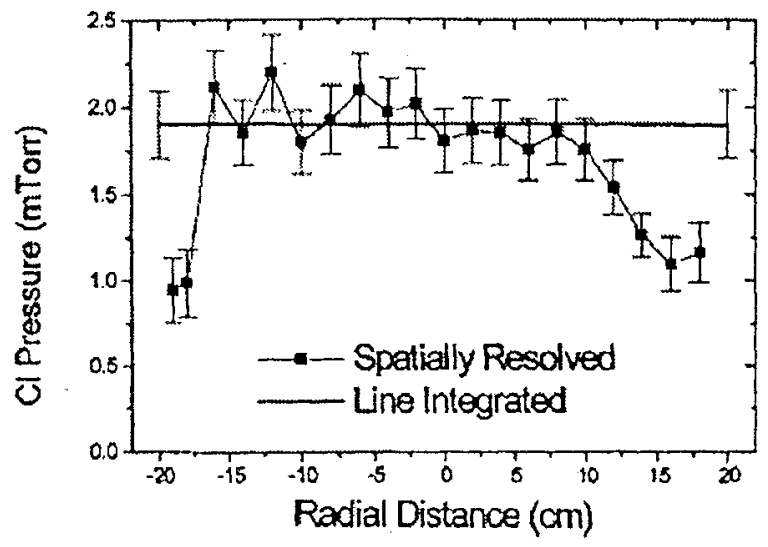

(b)

Fig. 5. Spatial profiles of $\mathrm{Cl}$ in a $\mathrm{Cl}_{2}$ discharge and $\mathrm{F}$ in a $\mathrm{CF}_{4}$ discharge.

The major parameter that is not well known is the wall recombination coefficients. Without this knowledge, models have a free parameter that limits their usefulness. Recent work (both theoretical and experimental) has begun to impact this problem. For example, Meeks et al. [58] predicted the dependence of species concentrations on the atomic-chlorine recombination rate at the walls of an HDP reactor. Comparison of model predictions to measured composition trends showed the wall-recombination probability for chlorine atoms on a chlorinated anodized-aluminum surface must exceed 0.1 . Panon et al. [59] have used actinometry [60] to establish the wall recombination probability as a function of the temperature of a Pyrex wall for $\mathrm{O}$ atoms flowing in a DC glow discharges for pressures ranging from 0.36-2 torr. Sarfaty et al. have shown (see Fig. 5) that the concentration of fluorine in a $\mathrm{CF}_{4}$ plasma increases rapidly near the wall while the concentration of atomic chlorine decreases rapidly near the wall when the same tool is operated with $\mathrm{Cl}_{2}$.

\section{Plasma CONTROL}

\section{A. Radial Profiles}

Radial (and azimuthal) uniformity of etch rate, selectivity, etc., is a goal of semiconductor processing. Uniformity can be accomplished by either achieving uniformity separately for charged particle, neutral species, and wafer parameters across the wafer or by adjusting plasma and neutral parameters 


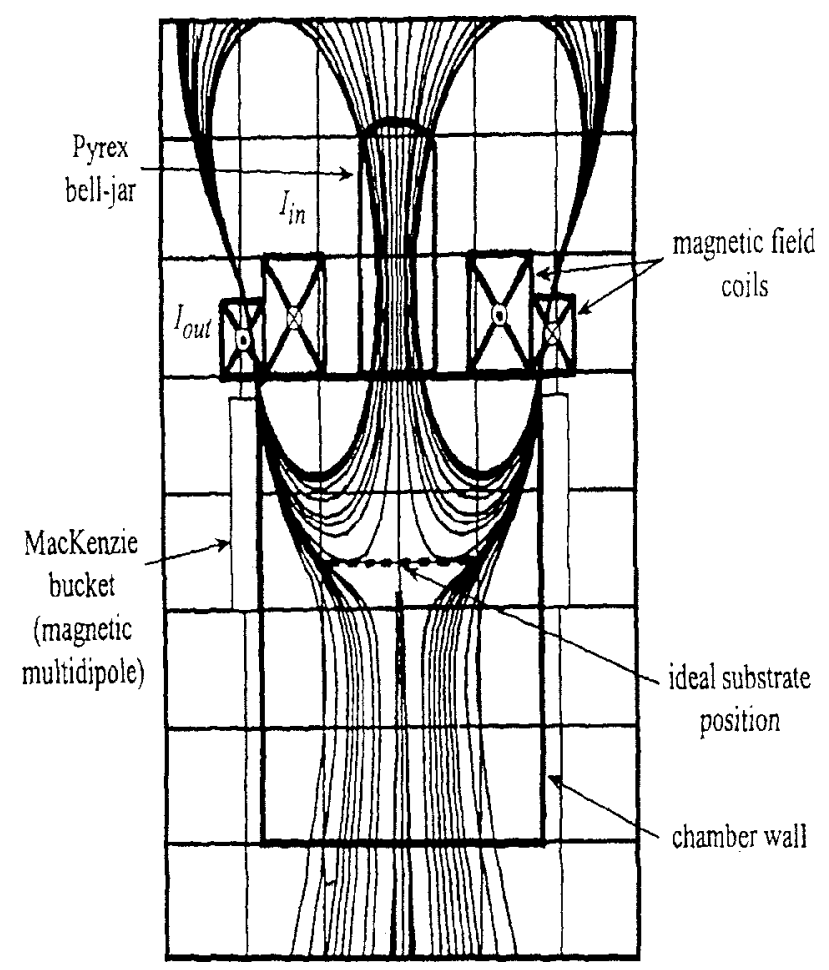

Fig. 6. Schematic of magnetic field coils in MORI source together with a representative $B$ field. The wafer is normally located at the magnetic cusp.

to compensate for variations across the wafer. While both approaches work, the latter is often easier to achieve than the former. Unfortunately, the compensation approach does not scale well with wafer size and with varying chemistries.

Establishing process windows continues to be a major step in the application of plasma tools. The standard approach is to carry out statistically designed experiments in which all the tool parameters that can be varied are varied. The success of this approach depends on the extent to which plasma parameters near the wafer depend on the available tool parameter control knobs. Many investigators have found that etch rate and selectivity depend on the ion energy delivered to the wafer [61], [62]. This in turn depends on the self-bias voltage since most of the ion energy is acquired in the plasmawafer sheath. Thus self-bias voltage is a good control knob for overall selectivity and overall etch rate but does not provide a way to adjust the radial etch rate or selectivity profile. Radial profile parameters are now controlled by careful tool design such as coil location in a planar inductive source or careful design of showerhead gas feeds combined with careful choice of wall materials and temperature.

1) MORI Source: In most tools, appropriate control knobs are not available for radial selectivity and etch rate control. A notable exception is the M0RI helicon source [63]. This tool is shown schematically in Fig. 6.

The wafer is located at a magnetic cusp where the magnetic field is close to zero. One unique feature of this source is that the cusp field is produced by two concentric magnetic field coils rather than two coils located at different axial locations. Radial etch rate control is achieved by fine tuning the cusp magnetic field by varying the relative currents in the coils. A
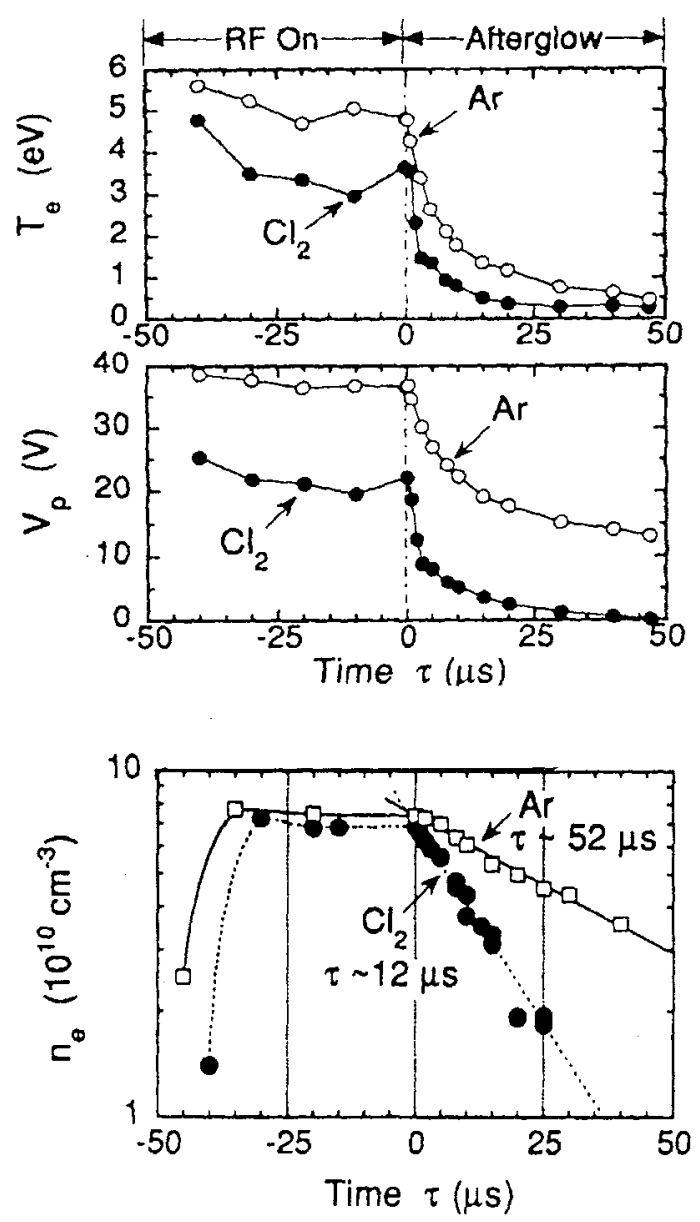

Fig. 7. Experimental data [39] for plasma decay in $\mathrm{Cl}_{2}$ and $\mathrm{Ar}$ afterglow plasmas.

variety of phenomena contribute to the radial etch rate profile. These include the RF power deposition profile, capacitive coupling, the neutral density profile, and the electron cyclotron resonance at 4.7 gauss for $13.56 \mathrm{MHz}^{31}$.

2) Multiple Sources: An alternative approach is to employ two or more separately controlled inductive coils or helicon sources. Such sources require much more attention to maintain uniformity and symmetry is not guaranteed. For example, Heinrich et al. describe a high-density plasma tool for large area flat panel display etching [64]. Plasma was produced by an array of four inductively coupled plasma sources driven by one common $13.56 \mathrm{MHz}$ generator. A second RF generator serves for substrate biasing. The substrate was $600 \times 400 \mathrm{~mm}^{2}$. Chen et al. have described a large array of helicon sources [65].

3) Small Source: Yet another alternative for achieving uniformity is to use a source which is smaller than the object being etched. For example, a large flat panel display can be moved at a constant rate under a uniform line source, which only matches the transverse dimension of the flat panel [66].

\section{B. Species Control of Selectivity}

1) RF Modulation: RF modulation has the potential of becoming a very useful "control knob." In afterglow plasmas, the electron density, temperature, and plasma potential all decay (see Fig. 7) [67], [68]. With the $T_{e}$ decay, negative 
ion production can be enhanced. At the same time, the gas species continually vary. By varying the afterglow time, i.e., the modulation duty cycle, with RF at a constant frequency, it is possible to achieve continuous variation of several plasma parameters. This approach has the important advantage that it does not require physical modification to the interior of plasma processing tools.

2) Decoupled Plasma and Neutrals: Plasma chemists have succeeded in separating plasma chemistry from plasma physics. There are two different approaches to decoupling the roles of ions and neutral species. One is to employ "downstream" sources [69] in which the plasma is allowed to decay spatially leaving mostly neutral species. This approach is employed in photoresist ashing tools in which oxygen plasmas serve as sources of atomic oxygen and ozone. The other approach to decoupling the roles of ions and electrons is to take advantage of plasma afterglows. Both work because the particle confinement time of ions is generally much less than the neutral radical species.

\section{SOME REMAINING PROBLEMS}

\section{A. Radial Uniformity}

As wafers grow in size, radial uniformity is becoming an increasingly important issue. Radial uniformity must be achieved etch rate, selectivity, anisotropy, wafer charging, and wafer cooling and heating. Radial uniformity must be independent of aspect ratio and structure location on the wafer.

\section{B. Wafer Charging Phenomena}

A variety of problems have been at least partially attributed to nonuniform wafer charging. Among these are radiation damage, notching, and aspect ratio dependent etching. Nonuniform charging can be the result of pattern layout on the wafer or of nonuniform plasma charged particle or neutral particle radial profiles. Ramp voltage breakdown measurements were shown to be correlated with the presence of plasma nonuniformities across the gate-oxide layers of the MOS capacitor test structures [70]. Nonuniform profiles can be addressed by careful source design.

1) Aspect Ratio-Dependent Charging: Aspect ratio dependent etching can be the result of reduction of ion anisotropy. Photoresist and dielectric charging deflects ions accelerated by sheaths resulting in reduced etch rates at the bottom of high aspect ratio features as well as sidewall bowing. This is shown schematically in Fig. 8. Recent experiments [71] have shown this effect can be eliminated by using electron beams to discharge positive dielectric charging (as shown in Fig. 9).

2) Notching: Notching is localized sidewall etching. It is found at the bottom of an outermost line located next to a wide space after over etching a poly-Si line and space structure (see Fig. 10 [72]). Notching is the result of ion deflection toward the line, which has a lower potential from receiving more electrons from a side facing the wide space.

The origin of notching can be understood as follows (see Fig. 11). Ion acceleration in the plasma wafer sheath results in an anisotropic ion velocity distribution function, which allows

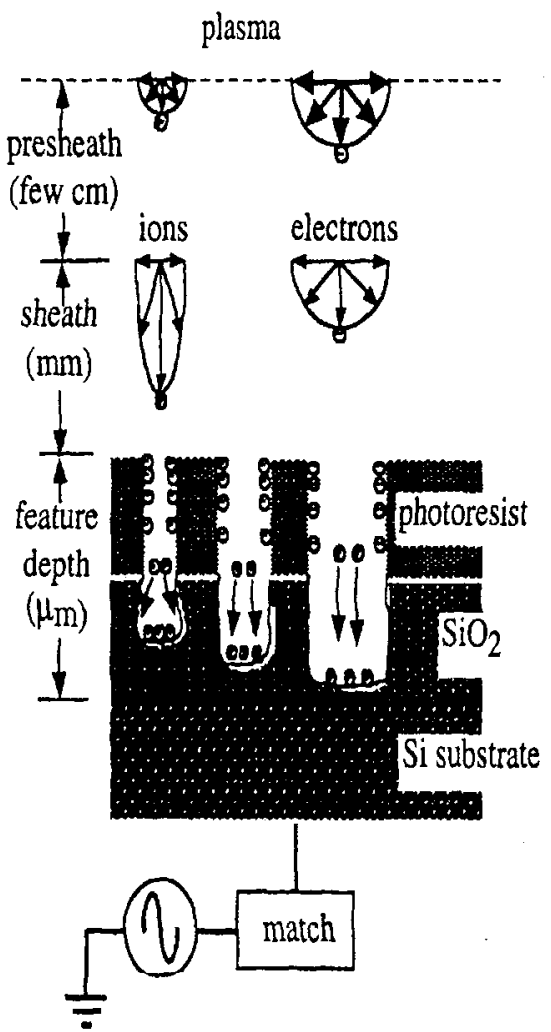

Fig. 8. Schematic of a model for differential charging as the source of aspect ratio dependent etching. Ion deflection by wall charging prevents some ions from reaching the bottom of the trench. Smaller aspect ratios correspond to deeper trenches.

ions to reach the bottom of the trench. On the other hand, the electron velocity distribution function is approximately isotropic both in the bulk plasma and in the sheath. This prevents the electrons from reaching the bottom of high aspect ratio sheaths and gives rise to net negative charging of photoresist at the top of the trench sidewalls. If a trench is etched in poly-Si on $\mathrm{SiO}_{2}$, the poly-Si sidewalls, below the photoresist, will be approximately equipotential surfaces. If the trench is an outermost line located next to a wide open space on the edge of a structure, electron conduction from the open space can partially discharge the positive charging at the trench bottom resulting in an electric field which directs ions asymmetrically into the interface between the poly-Si and the $\mathrm{SiO}_{2}$ near the bottom of the trench. Giapis et al. [73] and McVittie et al. [74] have argued the ions are directly responsible for the subsequent development of the notch. Notching has been addressed by lowering the electron temperature parallel to the surface [75], by the use of modulated discharges for unbiased wafers [76], [77] and by use of electron beams [67] and modulated source plus wafer bias for RF biased wafers. Sawin [78] has argued the directed ion flux only serves to remove a passivating layer and that the subsequent etch notching is the result of stress enhanced chemistry at the interface between the poly-Si and $\mathrm{SiO}_{2}$.

Notching has also been observed in overetching of widely separated lines (see Fig. 12) [71] and isolated structures when self bias is present. In these cases, nonuniform charging is the result of the ion anisotropy. 


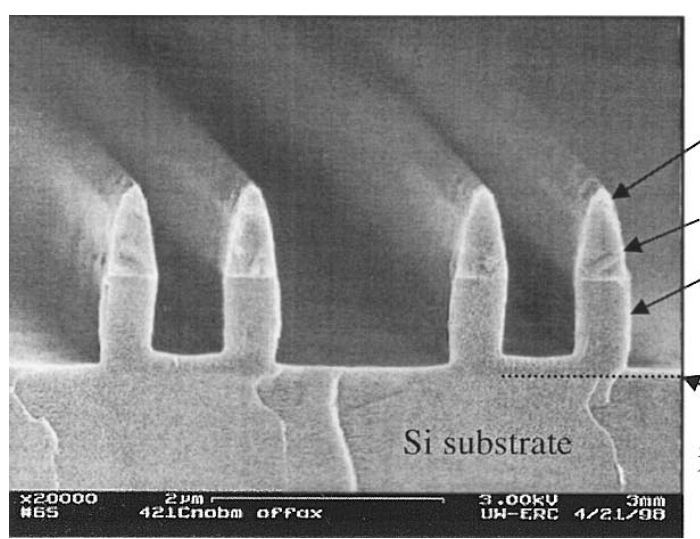

(a)

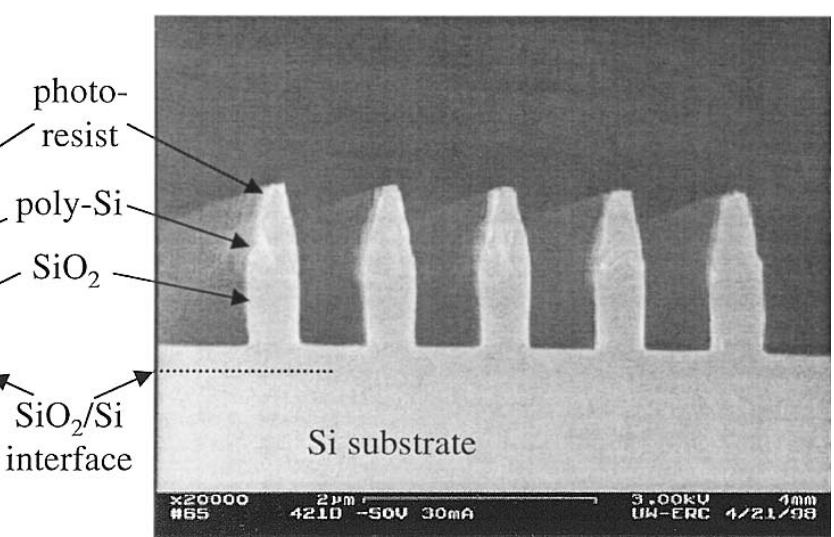

(b)

Fig. 9. Experimental data [71] showing: (a) aspect ratio dependent etching of $\mathrm{SiO}_{2}$ by a $\mathrm{C}_{2} \mathrm{H}_{2} \mathrm{~F}_{4}$ and (b) reduction in aspect ratio dependent resulting from discharging with an electron beam.

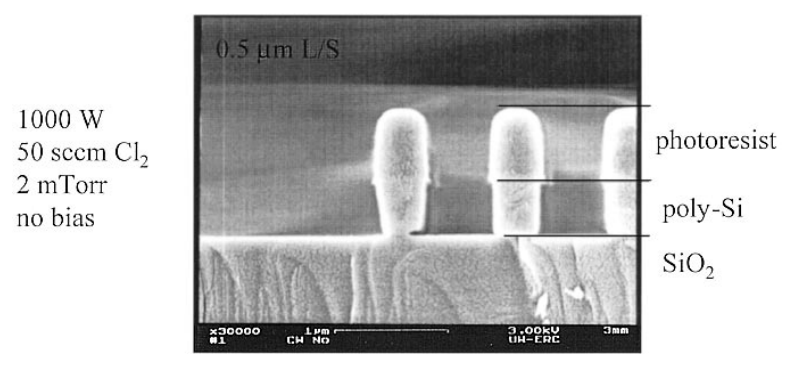

Fig. 10. Etch profiles measured with a line and space structure etched onto a $\mathrm{Si}$ wafer coated with $\mathrm{SiO}_{2}+$ poly-Si + photoresist.

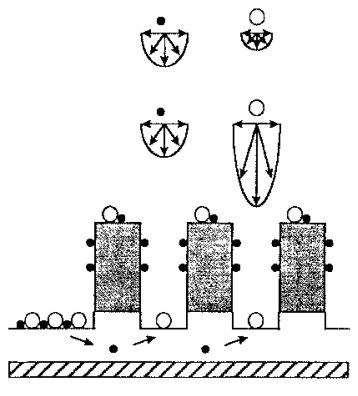

(a)

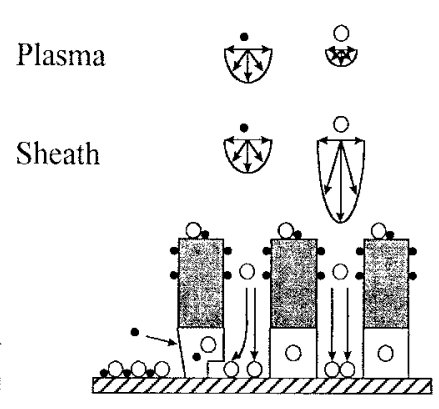

(b)
Fig. 11. Cartoon of the origin of the notch structure shown Fig. 10.

\section{Dust}

Great care is taken to avoid introduction of dust [79] in semiconductor applications. This often must be a two pronged strategy, which attacks dust from both the outside, and the inside of the processing tool itself. Fabs are based on impressive clean room facilities with class ten clean rooms having no more than ten dust particles per cubic foot or better. The use of polymer producing gases in processing plasmas leads to the formation of spherical "cauliflower-like" polymer dust (see Fig. 13) [80] in the plasma both from nucleation in the gas phase and by sheath electric fields pulling polymer from the surface of the substrate. Wall flaking is currently not well controlled. The polymer dust charges become trapped at the sheath-plasma boundary by the balance of the force of the sheath electric field and the force associated with collisions of ions and neutrals flowing out of the plasma as well as other forces. When the plasma is shut off and the sheath decays away, the dust falls to the wafer surface. Dust larger than the smallest structures on the wafer (e.g. $>0.3 \mathrm{~mm}$ is very detrimental to device operation. Grooves in electrodes have been developed as a technique to reduce dust growth in capacitive discharges [81]. The use of HDP plasmas have improved problems with dust formation by increasing the processing rate so dust has less time to form, but the problem is still present to some extent.

\section{Cu Deposition and Filling}

As the minimum feature size continues to decrease, the need for low-resistance local interconnections is becoming increasingly more important. To address this problem, the semiconductor industry is moving toward on-chip interconnects with copper metallization and polymer interlevel dielectrics to provide the lowest $R C$ delay, lowest parasitic coupling, and highest electromigration resistance. Such interconnect structures can be obtained by damascene patterning. In the "damascene" [82] process, high aspect ratio trenches etched in a dielectric are filled with metal and then planarized with chemical-mechanical polishing [83], [84]. The damascene $\mathrm{Cu}$ process makes use of ionized physical vapor deposition of $\mathrm{Cu}$. Copper is sputtered into a high density inductively produced argon plasma where it becomes ionized. This process can result in high $\mathrm{Cu}$ fractional ionization (as large as $85 \%$ ) leading to high directionality of deposition at a biased substrate which makes it possible to fill high aspect ratio trenches with copper.

As features continue to shrink, the major obstacle does not appear to be the plasma but rather lithography. However, I believe that plasma physics in the form of presheath scattering of ions will provide the eventual limit to anisotropy [85]. In HDP tools, presheath lengths are determined by the ion-neutral collision lengths [86], which are the order of a few $\mathrm{cm}$. Ionneutral collisions allow ions to gain velocity parallel to the wafer surface that can be a significant fraction of the ion acoustic velocity. This limits the maximum anisotropy that can be obtained and becomes increasingly more important as dimensions shrink and aspect ratios increase. 


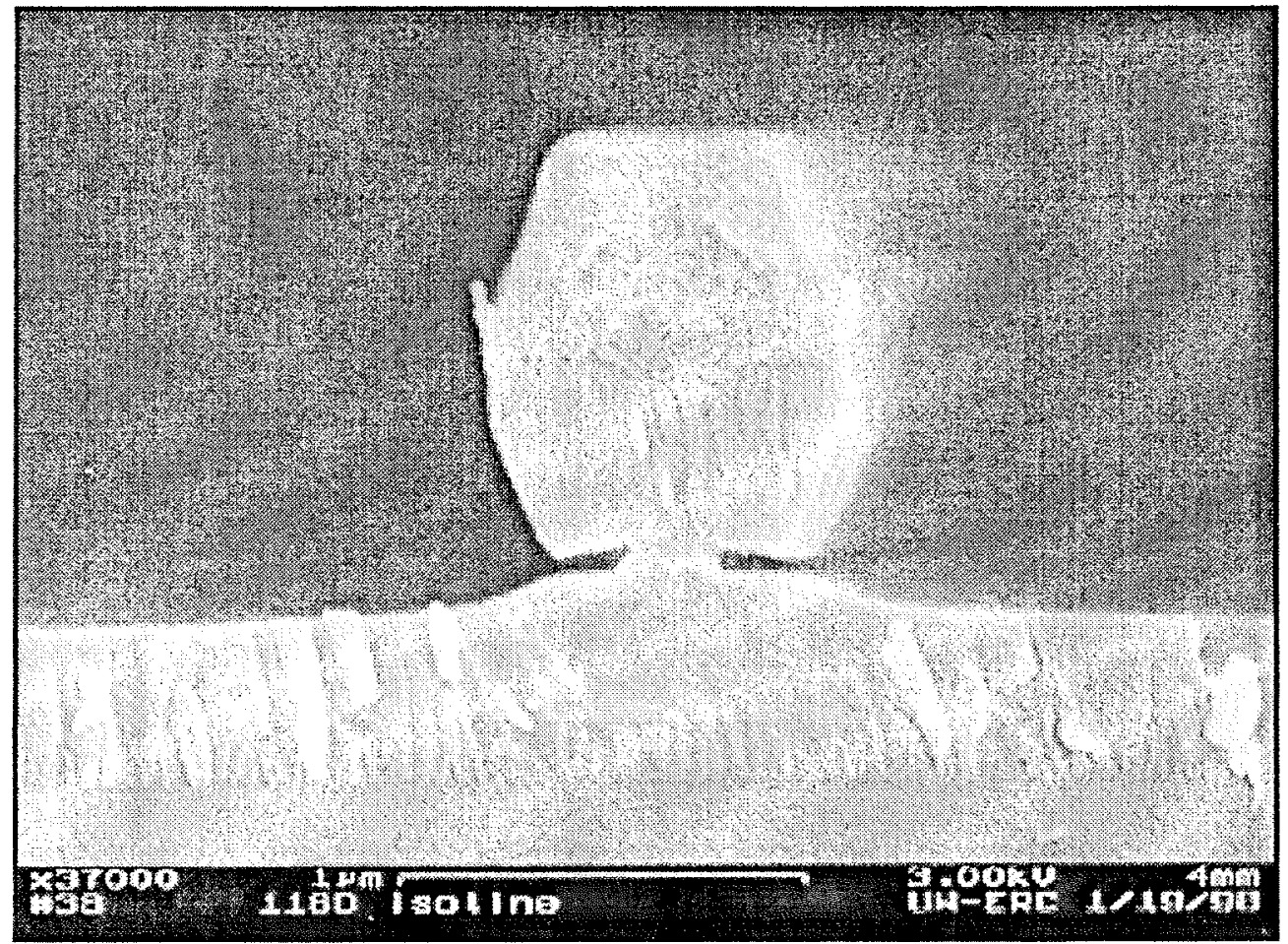

Fig. 12. Ten times over etch of an isolated 1_m poly-Si feature in a $\mathrm{Cl}_{2}$ plasma showing strong notching on both sides.

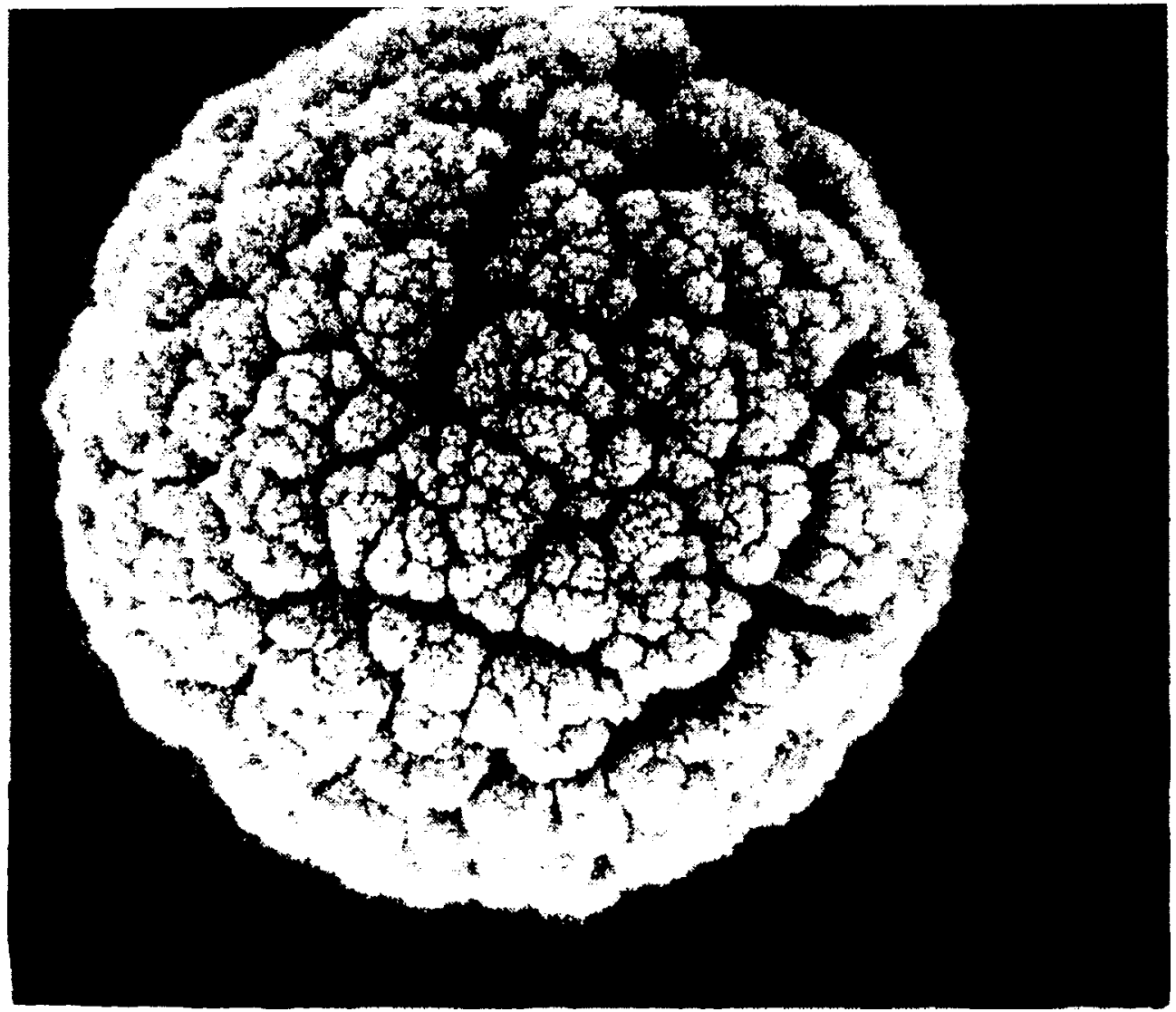

Fig. 13. SEM photo of cauliflower-like dust $($ diam. $=650 \mathrm{~nm})$. 


\section{REFERENCES}

[1] J. R. Conrad, J. L. Radtke, R. A. Dodd, and F. J. Worzala, "Plasma source ion-implantation technique for surface modification of materials," J. Appl. Phys., vol. 62, no. 11, pp. 4591-4596, Dec. 1987.

[2] S. M. Malik, D. E. Muller, K. Sridharan, R. P. Fetherston, and J. R. Conrad, "Distribution of incident ions and retained dose analysis for a wedge-shaped target in plasma source ion-implantation," J. Appl. Phys., vol. 77, no. 3, pp. 1015-1019, Feb. 1995.

[3] S. M. Bobbio, "A review of magnetron etch technology," Proc. SPIE Int. Soc. Opt. Eng., vol. 1185, pp. 262-77, 1990.

[4] S. M. Gorbatkin, D. B. Poker, R. L. Rhoades, C. Doughty, L. A. Berry, and S. M. Rossnagel, "Cu metallization using a permanent magnet electron cyclotron resonance microwave plasma/sputtering hybrid system," J. Vac. Sci. Technol., vol. B14, no. 3, pp. 1853-1859, May 1996.

[5] D. M. Manos and D. L. Flamm, Eds., Plasma Etching, An Introduction (and references therein). Boston, MA: Academic, 1989.

[6] M. Boulos, P. Fauchais, and E. Pfender, Thermal Plasmas, Fundamentals and Applications, vol. 1. New York: Plenum, 1994.

[7] R. M. Overney, H. J. Gutherodt, and S. Hild, "Corona-treated isotactic polypropylene films investigated by friction force microscopy," J. Appl. Phys., vol. 75, no. 3, pp. 1401-1404, Feb. 1994

[8] D. Zhang, Q. Sun, and L. C. Wadsworth, "Mechanism of corona treatment on polyolefin films," Polym. Eng. Sci., vol. 38, no. 6, pp. 965-970, June 1998.

[9] U. Kogelschatz, B. Eliasson, and W. Egli, "Dielectric-barrier discharges, principle and applications," J. Phys. IV, vol. 7, no. C4, pp. 47-66, Oct. 1997.

[10] P. P. Tsai, L. C. Wadsorth, and J. R. Roth, "Surface modification of fabrics using a one-atmospere glow discharge plasma to improve fabric wettability,” Textile Res. J., vol. 67, no. 5, pp. 359-369, May 1997.

[11] P. Maguire, J. Molloy, and S. J. Laverty, et al., "Etching characteristics of tin oxide thin films in argon-chlorine radio frequency plasmas," $J$ Vac. Sci. Technol., vol. A14, no. 6, pp. 3010-3016, Nov.-Dec. 1996.

[12] F. Heinrich, U. Banziger, and A. Jentzsch, G. Neumann, C. Huth, "Novel high-density plasma tool for large area flat panal display etching," $J$. Vac. Sci. Technol., vol. B14, no. 3, pp. 2000-2004, May-June 1996.

[13] E. Pfender, "Advances in modeling of the thermal spray process," $J$. Therm. Spray Technol., vol. 6, no. 2, pp. 126-128, June 1997.

[14] The National Technology Roadmap For Semiconductors Technology Needs, Semiconductor Industry Association, 1997 Ed..

[15] R. R. Schaller, "Moore's law: Past, present, and future," IEEE Spectrum, vol. 34:6, no. 52, 1997.

[16] C. G. Bell, "Beyond Moore's Law," IEEE Sprectrum, vol. 34, no. 6, pp. 56-56, June 1997.

[17] M. A. Lieberman, A. J. Lichtenberg, and S. E. Savas, "Model of magnetically enhanced capacitive RF discharges," IEEE Trans. Plasma Sci., vol. 19, pp. 189-196, Apr. 1991.

[18] J. Hopwood, "Review of inductively coupled plasma for plasma processing," Plasma Sources Sci. Technol., vol. 1, pp. 109-116, May 1992.

[19] J. H. Keller, "Inductive plasmas for plasma processing," Plasma Sources Sci. Technol., vol. 5, no. 2, pp. 166-172, May 1996.

[20] R. W. Boswell and F. F. Chen, "Helicons-The early years," IEEE Trans. Plasma Sci., vol. 25, pp. 1229-1244, Dec. 1997.

[21] F. F. Chen and R. W. Boswell, "Helicons-The past decade," IEEE Trans. Plasma Sci., vol. 25, pp. 1245-1257, Dec. 1997

[22] W. M. Holber, Electron Cyclotron Resonance (ECR) Ion Sources, Handbook of Ion Beam Technology, Principles, Deposition, Film Modification and Synthesis, J. J. Cuomo, S. M. Rossnagel, and H. R. Kaufman, Eds. Park Ridge, NJ: Noyes.

[23] H. Sugai, I. Ghanashev, and M. Nagatsu, "High-density flat plasma production based on surface waves," Plasma Sources Sci. Technol., vol 7, no. 2, pp. 192-205, May 1998.

[24] M. A. Lieberman and A. J. Lichtenberg, Principles of Plasma Discharges and Materials Processing. New York: Wiley, 1994.

[25] R. d'Agostino, Ed., Plasma Deposition, Treatment, and Etching of Polymers. San Diego, CA: Academic, 1990.

[26] V. A. Godyak, R. B. Piejak, and B. M. Alexandrovich, "Ion flux and ion power losses at the electrode sheaths in a symmetrical RF discharge," J. Appl. Phys., vol. 69, no. 6, pp. 3455-3460, Mar. 1991.

[27] Z. Zakrzewski and M. Moisan, "Plasma sources using long linear microwave field applicators-main features, classification and modeling," Plasma Sources Sci. Technol., vol. 3, pp. 379-397, Aug. 1995.

[28] M. Moisan, C. M. Ferreira, J. Hubert, J. Margot, and Z. Zakrzerski, Phenomena in Ionized Gases. K. H. Becker and W. E. Carr, Eds. Woodbury, NY: AIP, 1995, p. 25

[29] S. Shinohara, S. Takechi, and Y. Kawai, "Effects of axial magnetic field and farada shield on characteristics of RF produced plasma using spiral antenna," Jpn. J. Appl. Phys., vol. 135, no. 8, pp. 4503-4508, Aug. 1996.
[30] H. Sugai, K. Nakamura, and K. Suzuki, "Electrode coupling of antenna and the shielding effects in inductive RF plasmas," Jpn. J. Appl. Phys. vol. 133, no. 4B, pp. 2189-2193, Apr. 1994.

[31] A. R. Ellingboe and R. W. Boswell, "Capacitive, inductive and heliconwave modes of operation of a helicon plasma source," Phys. Plasmas, vol. 3, no. 7, pp. 2797-2804, July 1996.

[32] T. Lho, N. Hershkowtiz, J. Miller, W. Steer, and G. H. Kim, "Azimuthally symmetric pseudosurface and helicon wave propagation in an inductively coupled plasma at low magnetic field," Phys. Plasmas, vol. 5, no. 9, pp. 3135-3142, Sept. 1998.

[33] J. E. Stevens, M. J. Sowa, and J. L. Cecchi, "Helicon plasma source excited by a flat spiral coil," J. Vac. Sci. Technol. A, vol. 13, no. 5, pp. 2476-2482, Sept.-Oct. 1995

[34] N. Hershkowitz, J. Ding, R. A. Breun, R. T. S. Chen, J. Meyer, and A. K. Quick, "Does high density low pressure etching depend on the type of plasma source," Phys. Plasmas, vol. 3, no. 5, pp. 2197-2202, May 1996

[35] J. R. Woodworth, M. E. Riley, D. C. Meister, B. P. Aragon, M. S. Le, and H. H. Sawin, "Ion energy and angular distributions in inductively coupled radio frequency discharge in argon," J. Appl. Phys., vol. 80:3, no. 1, pp. 1304-1311, Aug. 1996

[36] S. Samukawa and T. Tsukada, "Essential points for precise etching processes in pulse-time-modulated high-density, low-pressure discharges," J. Vac. Sci. Technol. A, Pt. 1, vol. 15, no. 3, pp. 643-646, May-June 1997.

[37] M. A. Lieberman and S. Ashida, "Global models of pulse-powermodulated high-density, low-pressure discharges," Plasma Sources Sci. Technol., vol. 5, no. 2, pp. 145-158, May 1996.

[38] S. Ashida and M. A. Lieberman, "Spatially averaged (global) model of time modulated high density chlorine plasmas," Jpn. J. Appl. Phys., vol. 36, no. 2, pp. 854-861, Feb. 1997.

[39] M. Harper, private communication, 1997

[40] G. Hwang and K. Giapis, "On the origin of the notching effect during etching in uniform high density plasmas," J. Vac. Sci. Technol., vol. B15, no. 1, pp. 70-87, Jan.-Feb. 1997.

[41] C. Charles and R. W. Boswell, "Breakdown, steady-state, and decay regimes in pulsed oxygen helicon diffusion plasmas," J. Appl. Phys. vol. 78, no. 2, pp. 766-773, July 1995.

[42] K. H. R. Kirmse, A. E. Wendt, S. B. Disch, J. Z. Wu, I. C. Abraham, J. A. Meyer, R. A. Breun, and R. C. Woods, " $\mathrm{SiO}_{2}$ to Si selectivity mechanisms in high density fluocarbon plasma etching," J. Vac. Sci. Technol. A., pp. 710-715, July-Aug. 1996.

[43] E. Stoffels, W. W. Stoffels, D. Vender, M. Kando, G. M. W. Kroesen, and F. J. Dehoog, "Negative-ions in a radiofrequency oxygen plasma," Physical Rev., Pt. B, vol. E51, no. 3, pp. 2425-2435, Mar. 1995.

[44] T. H. Ahn, K. Nakamura, and H. Sugai, "Negative ion measurements and etching in a pulsed-power inductively coupled plasma in chlorine," Plasma Sources Sci. Technol., vol. 5, no. 2, pp. 139-144, May 1996.

[45] L. D. Tsendin, "One-dimensional analytical model of the transition from a townsend discharge to a glow discharge at high pressures," Sov. Phys.-Tech. Phys., vol. 34, no. 11, pp. 1239-43, Nov. 1989.

[46] A. J. Lichtenberg, I. G. Kouznetsov, Y. T. Lee, M. A. Lieberman, I D. Kaganovich, and L. D. Tsendin, "Modeling plasma discharges at high electronegativity," Plasma Sources Sci. Technol., vol. 6, no. 3, pp. 437-449, Aug. 1997

[47] N. Hershkowitz and R. A. Breun, "Diagnostics for plasma processing (etching plasmas) (invited)," Rev. Sci. Instrum., vol. 68, no. 1, pp. 880-885, Jan. 1997.

[48] K. H. Chew, J. Chen, and R. C. Woods, J. L. Shohet, "Silicon-oxide deposition in an electron-cyclotron-resonance plasma with microwave spectroscopic monitoring of SiO," J. Vac. Sci. Technol. A, vol. 13, no. 5, pp. 2483-2489, Sept.-Oct. 1995.

[49] R. C. Woods, Infrared Diode Laser Absorption Spectroscopy As A Plasma Chemical Diagnostic In Handbook Of Thin Film Process Technology., D. A. Glocker and S. I. Shah, Ed. Bristol, U.K.: IOP, 1997.

[50] V. M. Donnelly in Plasma Diagnostics, vol. 1, O. Auciello and D. L. Flamm, Ed. Boston, MA: Academic, 1989.

[51] P. Biolsi, D. Morvay, L. Drachnik, and S. Ellinger, "An advanced endpoint detection solution for $<1 \%$ open areas," Solid State Technol., vol. 39 , no. 12 , p. 59 , Dec. 1996 .

[52] H. L. Maynard, E. A. Rietman, J. T. C. Lee, and D. E. Ibbotson, "Plasma etching endpointing by monitoring radio-frequency power systems with an artificial neural network," J. Electrochem. Soc., vol. 143, no. 6, pp. 2029-2035, June 1996

[53] M. Sarfaty, C. Baum, M. Harper, N. Hershkowitz, and J. L. Shohet, "Real-time monitoring and control of plasma etching," Jpn. J. Appl. Physics, Pt 1, vol. 37, no. 4B, pp. 2381-2387, Apr. 1998.

[54] K. Wong, D. S. Boning, H. H. Sawin, S. W. Butler, and E. M. Sachs, 
"Endpoint prediction for polysilicon plasma etch via optical emission interferometry," J. Vac. Sci. Technol., vol. A15, no. 3, pp. 1403-1408, 1997.

[55] R. S. Wise, D. P. Lymberopoulos, and D. J. Economou, "Rapid twodimensional self-consistent simulation of inductively coupled plasma and comparison with experimental data," App. Phys. Let., vol. 68, no. 18, pp. 2499-2501, Apr. 1996.

[56] Ch. Wu, M. Meyyapan, and D. J. Economou, "Special issue on modeling and simulation of collisional low-temperature plasmas," IEEE Trans. Plasma Sci., vol. 23, pp. 501-502, Aug. 1995.

[57] U. Kortshagen, C. Busch, and L. D. Tsendin, "On simplifying approaches to the solution of the boltzmann equation in spatially inhomogeneous plasmas," Plasma Sources Sci. Technol., vol. 5, no. 1, pp. 1-17, Feb. 1996

[58] E. Meeks, J. W. Shon, Y. Ra, and P. J. Jones, "Effects of atomic chlorine wall recombination-comparison of a plasma chemistry model with experiment," Vac. Sci. Tech. A, vol. 13, no. 6, pp. 2884-2889, Nov.-Dec. 1995.

[59] D. Pagnon, J. Amorin, J. Nahorny, M. Touzeau, and M. Vialle, "On the use of actinometry to measure the dissociation in 0-2 DC glowdischarges-determination of the wall recombination probability," $J$. Phys. D, Appl. Phys. 28, vol. 9, no. 14, pp. 1856-1868, Sept. 1995.

[60] J.-S. Jenq, J. Ding, J. W. Taylor, and N. Hershkowitz, "Absolute fluorine atom concentrations in RIE and ECR $\mathrm{CF}_{4}$ plasmas measured by actinometry," Plasma Sources Sci. Technol., vol. 3, no. 2, pp. 154-161, May 1994.

[61] J. Ding, J.-S. Jenq, G. H. Kim, H. L. Maynard, J. S. Hamers, N Hershkowitz, and J. W. Taylor, "Etching rate characterization of $\mathrm{SiO}_{2}$ and Si using ion energy electron-cyclotron-resonance plasma," J. Vac. Sci. Technol. A, vol. 11, no. 4, pp. 1283-1288, July-Aug. 1993.

[62] J. P. Chang and H. H. Sawin, "Kinetic study of low energy argon ion-enhanced plasma etching of polysilicon with atomic/molecular chlorine," J. Vac. Sci. Technol. A, vol. 15, no. 3, pp. 610-615, May-June 1997.

[63] G. R. Tynan, A. D. Bailey III, G. A. Campbell, R. Charatan, A. de Chambrier, G. Gibson, D. J. Hemker, K. Jones, A. Kuthi, C. Lee, T. Shoji, and M. Wilcoxson, "Characterization of an azimuthally symmetric helicon wave high density plasma source," J. Vac. Sci. Technol. A, vol. 15, no. 6, pp. 2885-2892, Nov.-Dec. 1997.

[64] U. Heinrich, A. Banziger, G. Jentzsch, and C. Neumann, "Novel highdensity plasma tool for large area flat panel display etching," J. Huth, Vac. Sci. Technol., vol. B14, no. 3, pp. 2000-2004, 1996.

[65] F. F. Chen, X. Jiang, J. D. Evans, G. Tynan, and D. Arnush, "Low-field helicon discharges," Plasma Phys. Control. Fusion, vol. 39, no. 5A, pp. 411-420, Sept-Oct. 1997.

[66] R. J. Markunas, private communication, 1997.

[67] T. H. Ahn, K. Nakamura, and H. Sugai, "Negative ion measurements and etching in a pulsed-power inductively coupled plasma in chlorine," Plasma Sources Sci. Technol., vol. 5, no. 2, pp. 139-144, May 1996.

[68] T. Mieno and S. Samukawa, "Generation and extinction characteristics of negative ions in pulse-time-modulated electron cyclotron resonance chlorine plasma," Plasma Sources Sci. Tech., vol. 6, no. 3, pp. 398-404, Aug. 1997.

[69] M. G. Blain, T. L. Meisenheimer, and J. E. Stevens, "Role of nitrogen in the downstream etching of silicon nitride," J. Vac. Sci. Technol. A, vol. 14, no. 4, pp. 2151-2157, July-Aug. 1996.

[70] J. B. Friedmann, J. L. Shohet, R. Mau, N. Hershkowitz, S. Bisgaard, S. M. Ma, and J. P. McVittie, "Plasma-parameter dependence of thinoxide damage from wafer charging during electron-cyclotron-resonance plasma processing," IEEE Trans. Semiconduct. Manufact., vol. 10, pp. 154-166, Feb. 1997.

[71] A. K. Quick, "Electron beam neutralization of large aspect ratio features during plasma etching," Ph.D. dissertation, University of Wisconsin, Madison, WI, 1998.

[72] N. Fujiwara, T. Maruyama, and M. Yoneda, "Profile control of poly-Si etching in electron-cyclotron-resonance plasma," Jpn. J. Appl. Phys. 1, vol. 34, no. 4B, pp. 2095-2100, Apr. 1995.

[73] G. S. Hwang, Giapis, "Electron irradiance of conductive sidewalls: A determining factor for pattern-dependent charging," J. Vac. Sci. Technol., vol. B15, no. 5, pp. 1741-1746, Sept.-Oct. 1997.

[74] T. Kinoshita, M. Hane, and J. P. McVittie, "Notching as an example of changing in uniform high density plasmas," J. Vac. Sci. Technol., vol. B14, no. 1, pp. 560-565, Jan.-Feb. 1996.

[75] N. Fujiwara, S. Ogino, T. Maruyama, and M. Yoneda, "Charge accumulation effects on profile distortion in ECR plasma etching," Plasma Sources Sci. Technol., vol. 5, no. 2, pp. 126-131, May 1996.

[76] S. Samukawa, "Pulse-time-modulated electron cyclotron resonance plasma etching for highly selective, highly anisotropic, and notch-free polycrystalline silicon patterning," vol. 47, no. 5167, Appl. Phys. Lett. 64, pp. 3398-3400, June 1994.

[77] S. Samukawa and K. Terada, "Pulse-time modulated electron cyclotron resonance plasma etching for highly selective highly anisotropic, and less-charging polycrystalline silicon patterning," J. Vac. Sci. Technol., vol. B12, pp. 3300-3305, 1997.

[78] H. H. Sawin, private communication, Dec. 1997

[79] D. B. Graves, J. E. Daugherty, M. D. Kilgore, and R. K. Porteous, "Charging transport and heating of particles in radiofrequency and electron cyclotron resonance plasmas," Plasma Sources Sci. Technol., vol. 3, no. 3, pp. 433-441, 1994

[80] A. Garscadden, B. N. Ganguly, P. D. Haaland, and J. Williams, "Overview of growth and behavior of clusters and particles in plasmas," Plasma Sources Sci. Technol., vol. 3, no. 3, pp. 239-245, 1994.

[81] G. S. Selwyn, "Optical characterization of particle traps," Plasma Sources Sci. Technol., vol. 3, no. 3, pp. 340-347, 1994

[82] C. A. Nichols, S. M. Rossnagel, and S. Hamaguchi, "Ionized physical vapor deposition of $\mathrm{Cu}$ for high aspect ratio damascene trench fill applications," J. Vac. Sci. Technol., vol. B14, no. 5, pp. 3270-3275, Sept.-Oct. 1996.

[83] F. B. Kaufman, D. B. Thompson, R. E. Broadie, M. A. Jaso, W. L. Guthrie, D. J. Pearson, and M. B. Small, "Chemical-mechanical polishing for fabricating patterned W metal features as chip interconnects," $J$. Electrochem. Soc., vol. 138, no. 11, pp. 3460-3465, 1991.

[84] N. Elbel, B. Neureither, B. Ebersberger, and P. Lahnor, "Tungsten chemical mechanical polishing," J. Electrochem Soc., vol. 145, no. 5, pp. 1659-1664, 1998.

[85] J. Zheng, R. P. Brinkmann, and J. P. McVittie, "The effects of the presheath on the ion angular-distribution at the wafer surface," $J$. Vac. Sci. Technol. A, vol. 13, no. 3, pp. 859-864, Part 1, May-June 1995.

[86] J. A. Meyer, G.-H. Kim, M. J. Goeckner, and N. Hershkowitz, "Measurements of the presheath in an electron cyclotron resonance etching device," Plasma Sources Sci. Technol., vol. 1, pp. 147-150, 1992.

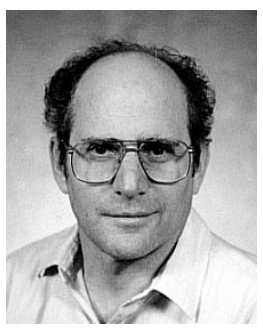

Noah Hershkowitz (SM'82-F'89) was born in Brooklyn, NY, on August 16, 1941. He received the B.S. degree in physics from Union College, Schenectady, NY, and the Ph.D. degree from the John Hopkins University, Baltimore, MD, in 1966.

He worked as an Instructor at The John Hopkins University until he joined the University of Iowa, Iowa City, as an Assistant Professor in 1967. From 1967 to 1981, he carried out Mossbauer effect studies of nuclear physics and magnetism, and from 1971 to 1981, he worked with experimental basic plasma physics. During leaves from the University of Iowa, he spent 1974-1975 and 1980-1981 at the University of California, Los Angeles, and the University of Colorado, Boulder. Since 1981, he has been Professor of Nuclear Engineering and Engineering Physics and Director of the Phaedrus Laboratory for Plasma Science at the University of Wisconsin, Madison. $\mathrm{He}$ has held the position of Irving Langmuir Professor at this institution since 1987. Since January 1997 he has been the Director of the Center for Plasma-Aided Manufacturing. His current research is a combination of basic plasma physics and plasma processing. He is a widely recognized expert in areas that include ion acoustic solutions, electrostatic shocks, double layers, plasma sheaths, emissive probes, electrostatic confinement in tendem mirrors, and ponderomotive force from ICRF. His most recent interest has been in plasma-aided manufacturing, especially plasma etching as well as to basic plasma physics. He has a well-established record in helping postgraduate students, editing and refereeing important journals, and in supporting the national fusion and basic plasma science program. He has published more than 237 journal articles.

Dr. Hershkowitz served as an Associate Editor of Physics of Fluids from 1981 to 1983 and has been a Divisional Editor of Physical Review Letters. $\mathrm{He}$ is the Editor-In-Chief of Plasma Sources-Science and Technology, which began publication in February 1992. In 1987, he received the IEEE Nuclear and Plasma Sciences Society Merdt Award. In 1993, he received the PSAC Award. He is a Fellow of the APS. He was Chairman of the APS-Division of Plasma Physics from 1990 to 1991. He was also Chairman of the NPSS Awards Committee and past Vice-president of NPSS. Additionally, he has also served on the IEEE Nuclear and Plasma Sciences Society Administrative Committee. He is a member of the PSAC Administrative Committee and has been the committee chairperson from January 1997 until December 1998. 